SHS Web of Conferences 17, 01002 (2015)

DOI: $10.1051 /$ shsconf/ 20151701002

(C) Owned by the authors, published by EDP Sciences, 2015

\title{
Empirical Research on Factors that Influence the Behavior Decision of Repeated Seed Purchase for Farmers - Field investigation based on 519 vegetable farmers in Wuhan City
}

\author{
Guoguang Kang ${ }^{1}$, Fang $\mathrm{Cai}^{2}$, Shengyong Zhang ${ }^{1}$ \\ ${ }^{1}$ Huazhong Agricultural University, Wuhan, Hubei, China \\ ${ }^{2}$ Hubei Academy of Forestry, Wuhan, Hubei, China
}

\begin{abstract}
This article makes an analysis on the factors and impact on decision of repeated seed purchase behavior for farmers by using the field investigation data from 519 vegetable farmers around Wuhan City and the binary Logit model and ordered Logit model. It is found from the research that: repeated seed purchase is a common phenomenon as $84 \%$ of sample farmers have this behavior: the factors, such as education degree, risk attitude, Perceived Value, seed quality, seed purchase convenience, relationship trust and obstacle transfer, will influence the behavior or willingness of farmers to repeatedly purchase the seeds. The farmers with higher education degree or risk preference are more willing to try out new varieties; Improving farmer's Perceived Value for the purchased seeds and the trust in distributors, as well as the relatively high seed quality, will increase farmer's willingness for repeated seed purchase; While the higher costs for information seeking, costs for technical study and other transfer obstacle factors have a significant prohibitive effect on the farmers to prevent them from purchasing new varieties of seeds, and they tend to make decision of repeated seed purchase.
\end{abstract}

Keywords. farmer; behavior decision; repeated purchase; vegetable growing

Crops seeds are the national strategic, basic and core industry. They are fundamental to boost the long-term stable development of agriculture and ensure the national safety of food. The massive seed market introduces many transnational leading seed enterprises, and they gradually take the dominant position in the market of seeds like vegetable and corn ${ }^{[1]}$. The domestic seed enterprises shall not only understand the improvement space for existing crop varieties and cultivate new varieties based on the advantages of seed quality, but also take the local advantages, find the thought and purchase preference of seed consumers and develop target marketing activity to acquire the advantageous position in the market competition. In the perspective of farmers, this article investigates the farmer's seed purchase decision and its impact factors, as well as discovers the consumption and purchase preference, for the purpose of improving the enterprise competitiveness and providing decision reference for vegetable seed enterprise and vegetable seed cultivation institution. 


\section{Reference review}

Seed purchase decision refers to the behavior selection of farmers, driven by interest, with maximum benefit based on their own resources, experience and environmental limitation according to the natural condition and social economy condition. According to the current references, the studies on behavior decision of farmer's seed (seedling) purchase mostly focus on the seed value $e^{[2,3]}$, agricultural subsidy policy implications ${ }^{[4]}$ and seed purchase influence factor ${ }^{[4-8]}$.

In the perspective of farmers, Yanjun $\mathrm{Li}$ and Lingxin Cai have researched the seed value, thinking that the elements of seed value can be divided according to the importance: inner core value, service, inner general value, brand, appearance and advertisement. They also suggest that the enterprise should focus on the development of seed variety, strengthen the brand construction and carry out services based on the behavior preference of farmers ${ }^{[2,3]}$. Qifeng Cui uses Probit model to fit the impact of comprehensive subsidy policy on farmer's seed purchase behavior, and suggests to classify the subsidies for different varietys of farmers ${ }^{[4]}$. Chengbing Chu applies Heckan selection model to analyze the behavior of cognition and acceptance for GMO technology, thinking that the householder's education degree, social capital, frequency of communication with villagers, fine breed subsidy and technical training have significantly positive impact on the cognition and acceptance, but with negative impact on the price of insect-resistant cotton seed ${ }^{[5]}$. Shiyin Zhu uses Logistic model to study the cognition and willingness of growing GM rice for rice farmers, thinking that the willingness of growing is influenced by both the self and external factors $^{[6]}$. Some experts notice the impact of agricultural cooperatives on the agricultural material purchase of farmers. In view of game theory, Xu Deyun has discussed about the dynamic game among farmer, production cooperation organization and agricultural material sellers, thinking that the farmers who join the production cooperation organization will efficiently avoid the risk of fake agricultural material so as to reach the Pareto Optimality ${ }^{[9]}$; But there are also some empirical studies indicating that most of the professional farmer cooperatives are just formalities without due effect. A large part of above references use Logistic or Probit model to conduct multiple regression analysis to study the influence factors that influence the farmer's decision of seed (seedling) purchase $^{[5-8]}$.

Therefore, based on the existing results, this article makes a deep investigation on the decision of seed purchase behavior for vegetable farmers and its influence factors. First, this article uses binary Logit model to analyze which factors will influence the repeated seed purchase behavior of farmers, and then applies ordered Logit model to further discuss about the influence degree of these factors on the repeated seed purchase decision of farmers, expecting to obtain valuable results.

\section{Research hypothesis and research method}

\subsection{Research hypothesis}

According to existing research results and relevant theories, as well as the detailed features of vegetable growing, this article divides the factors that influence the seed purchase behavior of vegetable farmers into the following three varieties.

(1) Basic features of householder. Basic features of householder include householder's age, time spent in growing vegetables, education degree, risk attitude, etc. (1). Householders of different ages have varied conceptions in seed purchase because they are different in physiology, mentality and social experience. The older farmers tend to be conservative and unwilling to try out new varieties when purchasing seeds. (2). The varied time spent in growing vegetable induces different production experience for farmers. The experienced farmers tend to select seeds based on experience.(3). The farmers with higher education degree will have a stronger ability to use the external information. They will be fully aware of the potential profits and risks in a new variety of seed when purchasing seeds, and are likely to have higher initiatives to try out new varieties of 
seeds. (4). The risk attitude of farmer will influence his trying out on the new varieties. The farmer repelled by risk tends to refuse something new and is more willing to purchase the seeds which were previously grown.

(2) Business features of farmer. The business features of farmer include, among other things, vegetable growing area, vegetable income proportion, vegetable growing mode and purpose, and whether to join the cooperatives. (1). When purchasing seeds, the farmers with larger vegetable growing area and with higher investment in the early stage of production tend to be more conservative; when purchasing seeds, the farmers with higher proportion of vegetable income in the total family income will tend to be more careful. This conservative and careful thought will mostly appear to be a repeated purchase behavior as the farmers fail to get adequate and efficient information. The small-scale growers that plant vegetables as food for their own families will be relatively casual about purchase of seeds. (2). The cooperatives have a certain right of speech in the process of purchasing production goods. Some of them uniformly purchase the seeds, fertilizers and other production goods, and the other recommend the brand of production goods for farmer's reference.

(3) Seed marketing factors. These factors include variables such as customer satisfaction, relationship trust and transfer obstacle. (1). Customer satisfaction mainly includes sensation for the seed value and the satisfaction degree to seed quality, service quality, brand reputation and purchase convenience. The brand reputation wins a public praise for the seed company or seed brand, and the farmers will recommend their neighbors about the brand, which increases the attraction and credibility of seeds. The distribution marketing theory says the customer satisfaction is the most leading factor that influences the behavior decision.(2). Relationship trust refers to the trust of farmers to distributors and the services provided thereby. The marketing theory says the customers tend to purchase or even repeatedly purchase the products from businesses with higher credibility.(3). The transfer obstacle can be construed as the risks and costs the farmers face and realize when they purchase other varieties of products. When purchasing seeds, the farmers will consider a wide range of costs, expenses and risks brought by changing the variety of seeds, and they will make decisions after weighing the gains and losses. The larger transfer obstacle will lead the farmers to have more willingness in second purchase, more possible to prevent them from purchasing new varieties of products. While, if the new products can bring or be expected to bring more profits, the farmers may be willing to try out the new products instead of repeatedly purchasing the original ones.

\subsection{Research method}

This study divides the farmer's behavior decision of seed purchase into the following two aspects: firstly, which factors will influence the farmer's behavior decision of repeated seed purchase; secondly, the influence degree of different factors on repeated seed purchase willingness. There are two possibilities in farmer's purchase decision: repeated seed purchase and trying out on new product. Use binary Logit model analysis to verify the factors that influence the farmer's behavior decision.

Establish the function expressions for odds of influencing the farmer's repeated seed purchase:

$$
\operatorname{Ln}\left(\frac{p_{i}}{1-p_{i}}\right)=\beta_{0}+\beta_{1} x_{i 1}+\ldots+\beta_{j} x_{i j}+\ldots+\beta_{n} x_{i n}+\mu_{i}
$$

In formula (1), $p_{i}$ refers to probability of farmer's repeated seed purchase; $\beta_{j}(\mathrm{j}=0,1, \ldots \ldots, \mathrm{n})$ are coefficients to be estimated; $\mu_{i}$ refers to random error term. According to the previous hypothesis, the explanatory variable $x_{i j}$ refers to respectively the householder's age, education degree, year spent in vegetable growing industry, risk attitude, vegetable growing area, growing mode, vegetable income proportion, participation in cooperative, Perceived Value, seed quality, brand reputation, seed purchase convenience, service quality, relationship trust and transfer obstacle. 
This article uses Likert scale of willingness to divide the farmer's seed purchase behavior decision into 5 levels, and applies the ordered Logit model in sorting probability model to analyze the influence degree of each factor on farme's behavior decision of repeated seed purchase. The detailed function expression is as follows:

$$
y_{i}^{*}=\beta_{0}+\beta_{1} x_{i 1}+\ldots+\beta_{j} x_{i j}+\ldots+\beta_{n} x_{i n}+\mu_{i}
$$

In formula (2), $\beta_{j}\left(\mathrm{j}=0,1, \ldots \ldots, \mathrm{n}\right.$ are coefficients to be estimated; $\mu_{i}$ refers to random error term. $y_{i}{ }^{*}$ refers to latent variable corresponding to a ranked variable $y_{i}$. If the number of observed sample is set as $\mathrm{N}, y_{i}$ will mean the rank 1 appears for $\mathrm{n}_{1}$ time, rank 2 for $\mathrm{n}_{2}$ times.... rank 5 for $\mathrm{n}_{5}$ times. According to the research methods of Dongmei Li and Luan Luo, this article uses maximum likelihood estimation function to estimate the ordered Logit function. Then, the maximum likelihood function of model (2) is as follows:

$$
L=\left[P\left(y_{i}=1 \mid X_{i}\right)\right]^{n_{1}}\left[P\left(y_{i}=2 \mid X_{i}\right)\right]^{n_{2}}\left[P\left(y_{i}=3 \mid X_{i}\right)\right]^{n_{3}}\left[P\left(y_{i}=4 \mid X_{i}\right)\right]^{n_{4}}\left[P\left(y_{i}=5 \mid X_{i}\right)\right]^{n_{5}}
$$

\section{Data source and sample description}

\subsection{Data source}

The data used in the research of this article was obtained through field investigation in concentrated vegetable growing villages and towns in suburbs of Wuhan by research group. As a vegetable base for suburbs of large city, the suburban district of Wuhan plays an important role in improving the self-sufficiency of vegetable and adjusting the vegetable price in Wuhan City. Based on the investigation design, this article selects regular vegetable farmers in 6 suburban districts in Wuhan (Eastern and Western Lake District, Xinzhou District, Caidian District, Huangpo District, Jiangxia District and Hannan District) as the objectives and randomly selects villages and vegetable farmers in the main vegetable production villages and towns (streets) for investigation. Field investigation was made between March-June 2013. We used question-answer method and delivered 600 questionnaires, of which 548 were returned, with 519 valid ones, validity rate $86.5 \%$. The varieties of vegetables grown by investigated objectives include root vegetables, onion ginger garlic, Chinese cabbage, cabbage, leafy vegetables, melons and vegetables, eggplant, bean class, etc..

\subsection{Sample description}

In the samples, male accounts for $66.3 \%$, female for $33.7 \%$. To get more accurate information in the actual investigation, the farmers we selected were the ones that actually purchase the seed in the vegetable farmer families, so it indicated the males took dominant place in seed purchase, a result similar to the conclusion of other scholars ${ }^{[10-12]}$. According to the samples, the basic conclusion for the vegetable farmers around Wuhan is that most of them are at middle age (45-59) (accounting for $48.4 \%$ ) who accepted junior high school education (accounting for $42.8 \%$. The couples (accounting for 78.0\%) grow vegetables for sales (accounting for 97.6\%), which are mainly grown in steel-framed greenhouse (accounting for 52.0\%), and the vegetable growing scale is below $0.4 \mathrm{hm}^{2}$ (accounting for 59.0\%). A similar conclusion will be drawn from Table 1; There are almost only three vegetable selling modes, namely "personally going to market for retail", "personally delivering to fixed retailers for sale" and "retailers going to farms for purchase", while there are few selecting to sell the vegetables in cooperatives or by orders (accounting for $1.9 \%$ ). It also reflects that the vegetable cooperatives do nothing in seed purchase, vegetable sales and other aspects related to the big market.

Farmer's Perceived Value (1 item), seed quality (6 items), brand reputation of seed (2 items), convenience of seed purchase ( 1 item) will be measured by Likert purchase satisfaction scale; Service quality ( 8 items) will be measured by service satisfaction scale for seed sellers; Reputation trust ( 8 items), transfer obstacle ( 7 items) and willingness of second purchase ( 4 items) will be 
measured respectively by relationship trust scale, transfer obstacle scale and purchase willingness scale. The relationship trust measures the credibility of farmers towards distributors and the service provided thereby in five dimensions, namely reliability, permanence, integrity, relationship network and enterprise brands; The transfer obstacle measures the transaction costs of purchasing seeds of other brands for farmers in four dimensions, namely transfer expense, transfer risk, sunk costs and study costs. The average of scores of each variable is above 3 , and $84 \%$ of the vegetable farmers choose to purchase the seeds of the same brand for a second time.

Table 1. Model variables selection and description of its process

\begin{tabular}{|c|c|c|c|}
\hline Name of variables & Variable measure & Average & $\begin{array}{l}\text { Standard } \\
\text { deviation }\end{array}$ \\
\hline Age of householder & Actual age & 51.63 & 10.29 \\
\hline $\begin{array}{l}\text { Number of labor } \\
\text { force }\end{array}$ & Number of people & 2.07 & 0.56 \\
\hline Education degree & $\begin{array}{l}\text { Primary school and below }=1 \text {; junior high } \text { school }=2 \text {; } \\
\text { senior high school and above }{ }^{a}=3\end{array}$ & 1.79 & 0.72 . \\
\hline $\begin{array}{l}\text { Year spent in } \\
\text { vegetable growing }\end{array}$ & $\begin{array}{l}\text { Farmer's actual year spent in vegetable growing } \\
\text { (year) }\end{array}$ & 20.11 & 11.47. \\
\hline Risk attitude & Preferential $=1 ;$ neutral $=2 ;$ repelled $=3$ & 2.40 & 0.85 \\
\hline Area & Farmer's actual area for vegetable growing $(\mathrm{mu})$ & 12.00 & 29.84. \\
\hline Growing mode & $\begin{array}{l}\text { Greenhouse }=1 ; \text { simple small greenhouse }=2 ; \text { field } \\
\text { growing }=3\end{array}$ & 1.38 & 0.67 . \\
\hline Purpose of growing & Food for self $=0 ;$ for sale $=1$ & 1.00 & 0.06 . \\
\hline Income proportion $\%$ & $\begin{array}{l}\text { Actual proportion of vegetable growing income in the } \\
\text { total family income }\end{array}$ & 83.25 & 20.69 . \\
\hline $\begin{array}{l}\text { Participation in } \\
\text { cooperatives }\end{array}$ & $\mathrm{Yes}=1, \mathrm{No}=0$ & 0.32 & 0.47 . \\
\hline Perceived Value & Likert 5 scale & 3.78 & 0.62 . \\
\hline Seed quality & Likert 5 scale & 3.81 & 0.37 . \\
\hline Brand reputation & Likert 5 scale & 3.79 & 0.54 \\
\hline Convenience & Likert 5 scale & 3.94 & 0.56 \\
\hline Service quality & Likert 5 scale & 3.11 & 1.01 . \\
\hline Relationship trust & Likert 5 scale & 3.69 & 0.54 \\
\hline Transfer obstacle & Likert 5 scale & 3.39 & 0.82 \\
\hline $\begin{array}{l}\text { Willingness of } \\
\text { second purchase }\end{array}$ & Likert 5 scale & 3.71 & 0.60 . \\
\hline Repeated purchase & $\mathrm{Yes}=1, \mathrm{No}=0$ & 0.84 & 0.37 . \\
\hline
\end{tabular}

\section{Analysis on the result estimated by model}

\subsection{Analysis on whether the farmers will repeatedly purchase the seeds}

As the age of householders is closely related to the years they spent in vegetable growing (relevant coefficient is 0.7 ), these two variables are to measure the social experience of householders, and the variable of householder's age will be deleted from the model.

(1) Influence of basic features of householder on repeated seed purchase of farmers. Two variables, the education degree and risk attitude, of householder have a significant impact on repeated seed purchase behavior of farmers. The education degree of householder has a positive impact on behavior decision of repeated seed purchase, and the influence of three education

\footnotetext{
${ }^{\text {a }}$ There are only 5 respondents with education degree of college and above, so this option is combined with education degree of senior high school and changed into education degree of senior high school and above.
} 
degrees is much different. The householders with education degree of junior high school and above have a preference for repeated seed purchase. The householders with preference for risks have a high probability in repeated purchase than the ones with neutral or repelled attitude to risks, which is compliant with what we expected. While the householders with neutral or repelled attitude to risks almost have no difference in behavior decision of repeated purchase. Furthermore, the years spent in vegetable growing does not have significant effect on the willingness of farmers to repeatedly purchase the seeds.

(2) Influence of business features of farmer on repeated seed purchase of farmers. Either greenhouse or simple small greenhouse are used by farmers to grow vegetables, and both will have no significant effect on repeated seed purchase. Vegetable growing area, proportion of vegetable income in the total family income and whether the farmers will join the cooperatives also have no significant effect on repeated seed purchase. It indicates the business features of farmer are not the main influence factors of farmer's seed purchase, or we can say, the business features of farmer requires other mediating variables to affect the behavior description of repeated seed purchase. It is not what we expected, and maybe the possible reason is related to the sample selection. The samples this article selected were the farmers from suburb in Wuhan. They have many information sources with smooth channels, which may in part offset the impact of business features of farmer on repeated seed purchase decision.

Table 2. Estimated results from model of whether the farmers will repeatedly purchase the seeds

\begin{tabular}{lllll}
\hline Variable & Coefficient & Standard error & Z value & Probability \\
\hline Primary school education and & 1.7459 & 0.5026 & 3.4738 & 0.0005 \\
below & 2.4188 & 0.4450 & 5.4360 & 0.0000 \\
Junior high school education & 0.0272 & 0.0179 & 1.5244 & 0.1274 \\
Year spent in vegetable growing & -0.9986 & 0.3752 & -2.6613 & 0.0078 \\
Risk preference & 0.9527 & 0.6879 & 1.3849 & 0.1661 \\
Neutral to risk & -0.0025 & 0.0079 & -0.3176 & 0.7508 \\
Growing area & 0.8460 & 0.7187 & 1.1771 & 0.2392 \\
Vegetables in greenhouse & -0.0432 & 0.7829 & -0.0552 & 0.9560 \\
Vegetables in small greenhouse & -0.0110 & 0.0095 & -1.1556 & 0.2478 \\
Income proportion & -0.0898 & 0.3952 & -0.2272 & 0.8203 \\
Participation in cooperatives & 1.7450 & 0.3566 & 4.8937 & 0.0000 \\
Perceived Value & 0.4077 & 0.4975 & 0.8195 & 0.4125 \\
Seed quality & 0.1212 & 0.4350 & 0.2785 & 0.7806 \\
Brand reputation & -0.8186 & 0.3711 & -2.2057 & 0.0274 \\
Convenience & -0.1792 & 0.1471 & -1.2179 & 0.2233 \\
Service quality & 0.9834 & 0.3648 & 2.6955 & 0.0070 \\
Relationship trust & 0.8188 & 0.3219 & 2.5437 & 0.0110 \\
Transfer obstacle & -10.4315 & 3.0072 & -3.4689 & 0.0005 \\
Intercept term & 0.3874 & Logarithmic value for & -139.6384 & \\
\hline McFadden R ${ }^{2}$ & & maximum likelihood & & \\
\hline
\end{tabular}

(3) Influence of seed marketing factors on repeated seed purchase of farmers. As shown in the estimated result in Table 2, most of the marketing factors have significant impact. The Perceived Value factor has the largest influence among all the marketing factors. The probability of repeated purchase of farmers with stronger Perceived Value for the purchased seeds will also be larger. Relationship trust and transfer obstacle has a positive impact on the behavior decision of repeated 
seed purchase. It indicates that the customers tend to repeatedly purchase the products from seed distributors with higher credibility. And if the transaction fee generated when farmers purchase the new varieties is higher, the probability to repeatedly purchase the original variety will also be larger. The convenience and service quality of distributors have a negative impact on the farmer's repeated seed purchase. It may be related to some convenience provided by distributors for farmers to purchase the seeds when the new varieties come into the market, but the impact of service quality is not so significant, which may be caused by the fact that the professional technical service level currently provided by a large part of seed distributors is relatively low. The seed quality and brand reputation have a positive impact on farmer's behavior decision of repeated purchase, but it's not significant. It may be caused by the fact that the qualities of vegetable seeds are not so different in the current market, and the brand effect has not been formed in relevant enterprises.

\subsection{Analysis on the influence degree of different factors on farmer's willingness of repeated seed purchase}

It can be found through comparison with Table 2 that the factors influencing farmer's behavior of repeated seed purchase also have an impact on the willingness of repeated seed purchase. Furthermore, the marks of influence factors significant both in Table 2 and Table 3 are the same, which shows the farmers are rational in the process of repeated seed purchase and the behavior of repeated seed purchase is a rational behavior limited by existing conditions even though repeated purchase of the same product is not conducive to promoting the new technology.

Table 3. Estimated results from the model of the influence degree of different factors on farmer's willingness of repeated seed purchase

\begin{tabular}{|c|c|c|c|c|}
\hline Variable & Coefficient & Standard error & $Z$ value & Probability \\
\hline Primary school education and below & 2.2198 & 0.4306 & 5.1555 & 0.0000 \\
\hline Junior high school education & 1.8041 & 0.3591 & 5.0243 & 0.0000 \\
\hline Year spent in vegetable growing & -0.0145 & 0.0125 & -1.1615 & 0.2455 \\
\hline Risk preference & -0.5112 & 0.3089 & -1.6550 & 0.0979 \\
\hline Neutral to risk & 0.2281 & 0.3964 & 0.5754 & 0.5650 \\
\hline Growing area & -0.0072 & 0.0057 & -1.2763 & 0.2019 \\
\hline Vegetables in greenhouse & -0.6716 & 0.5046 & -1.3309 & 0.1083 \\
\hline Vegetables in small greenhouse & -1.0743 & 0.5252 & -2.0456 & 0.0408 \\
\hline Income proportion & -0.0036 & 0.0068 & -0.5362 & 0.5918 \\
\hline Participation in cooperatives & 0.0999 & 0.2933 & 0.3406 & 0.7334 \\
\hline Perceived Value & 1.7472 & 0.2403 & 7.2708 & 0.0000 \\
\hline Seed quality & 0.8225 & 0.3724 & 2.2087 & 0.0272 \\
\hline Brand reputation & -0.0282 & 0.3127 & -0.0902 & 0.9281 \\
\hline Convenience & -0.2064 & 0.2437 & -0.8472 & 0.3969 \\
\hline Service quality & -0.1199 & 0.1311 & -0.9150 & 0.3602 \\
\hline Relationship trust & 1.4975 & 0.2704 & 5.5381 & 0.0000 \\
\hline Transfer obstacle & 0.5392 & 0.2193 & 2.4591 & 0.0139 \\
\hline Pseudo-R ${ }^{2}$ & 0.2758 & $\begin{array}{l}\text { Logarithmic value for } \\
\text { maximum likelihood }\end{array}$ & -306.5583 & \\
\hline
\end{tabular}

(1) Influence of basic features of householder on farmer's willingness of repeated seed purchase. Compared to the result in Table 2, the householder's education degree and risk features remain the significant factors. Lower education degree of householder leads to stronger 
willingness to repeatedly purchase the seeds, and the willingness of householders with risk preference to repeatedly purchase the seeds is obviously lower than that in other risk types. Years spent in vegetable growing have no significant impact on farmer's willingness of repeated seed purchase.

(2) Influence of business features of farmer on farmer's willingness of repeated seed purchase. Vegetable growing area, proportion of vegetable income in the total family income and whether the farmers will join the agricultural cooperatives also have no significant effect on repeated seed purchase. The growing mode will influence farmer's willingness of repeated seed purchase. Compared to field growing, the facility vegetable growing with sunk costs will reduce the willingness of farmers to repeatedly purchase the seeds. (Require comparison with conclusions in other references. If it's not compliant with the general research conclusion or common sense, it shall be deeply explained and interpreted).

(3) Influence of seed marketing factors on farmer's willingness of repeated seed purchase. The farmer's value sensation for purchased seed and the seed quality have a positive impact on farmer's willingness of repeated seed purchase, and if the Perceived Value is higher or the quality of purchased seeds is better, the farmer willingness of repeated seed purchase will also be stronger. Relationship trust and transfer obstacle has a positive impact on farmer's willingness of repeated seed purchase. It indicates that the customers tend to repeatedly purchase the products from seed distributors with higher credibility. And if the transaction fee generated when farmers purchase the new varieties is higher, the probability of willingness to try out new product will also be lower. Furthermore, the brand reputation, convenience and service quality has no significant impact. Of all the marketing factors, the farmer's Perceived Value and the relationship trust to distributors have the largest impact on farmer's willingness of repeated seed purchase.

\section{Research conclusion and policy inspiration}

\subsection{Main research conclusion}

This article uses investigation data from vegetable farmers around Wuhan to empirically analyze farmer's behavior decision of repeated seed purchase and its influence factors. It is found from the investigation that most of the sample farmers have a behavior of repeated seed purchase, and there's a difference in the degree of repeated seed purchase for farmers. The education degree, risk attitude and other householder's basic features, as well as seed quality, convenience, relationship trust, transfer obstacle and other marketing factors have a significant impact on the willingness of repeated seed purchase, but the business feature factors of farmers have no significant impact. The farmers with higher education degree or risk preference features are more willing to try out new varieties. Improving farmer's Perceived Value for the purchased seeds and the trust in distributors, as well as the relatively high seed quality, will increase farmer's willingness for repeated seed purchase; While the higher costs for information seeking, costs for technical study and other transfer obstacle factors have a significant prohibitive effect on the farmers, which prevents them from purchasing new varieties of seeds and hinders the promotion of new varieties.

\subsection{Policy inspiration}

The following policy inspirations will be obtained according to the above research conclusion: Firstly, the seed cultivation enterprises shall invest more in scientific research and market survey, make development and production according to demand of farmers, improve seed conclusion level by agricultural biotechnology, increase farmer's satisfaction with seed quality and improve farmer's Perceived Value for seeds. Secondly, the seed enterprises shall facilitate the brand construction, improve relationship marketing, establish and maintain the close and long-standing relation with farmers. Thirdly, the seed enterprises shall step up the publicity, and shall reduce the transfer obstacle and facilitate the promotion of new varieties by methods like voluntarily 
providing the farmers with sufficient seed supply information and growing technology through various channels.

\section{Acknowledgement}

A Study on Vegetable Price Fluctuation and Transmission Mechanism based on Dynamic CGE Model Simulation.

\section{References}

1. Bian, Q.L. On Advices of Seed Industry Fruits Assessment in National Scientific Bonus Review [J]. Chinese Agricultural Science Bulletin, 2012(35): 152-154.

2. Cai, L.X., Li Y.J., Yu, F. Analysis on Composition of Value Elements of Rice Seed-Based on Perspective of Farmer [J]. Journal of Huazhong Agricultural University (SOCIAL SCIENCE EDITION), 2012(02): 29-32.

3. Li, Y.J., Feng, S.S., Liu, S.T. Research on Composition of Value Elements of Vegetable Seed Based on Perspective of Farmer-Taking Tomato Seed for Example [J]. Seed, 2011(1): 79-83.

4. Cui, Q.F., Zhou, N., Sun, C.Q., etc. Analysis on Impact of Rice Farmer's Comprehensive Subsidy on Farmer's Investment of Production Factors-Taking the Seed Purchase Behavior of Farmers in Growing Crop Farming in Taipusiqi of Inner Mongolia[J]. Agricultural Economy and Management, 2014(02): 24-31.

5. Chu, C.B., Li, P. Empirical Research on Farmer's Cognition and Acceptance for GMO Technology-Taking the Growing of GM Bt Insect-resistant as an Example [J]. Collected Essays on Finance and Economics, 2013(01): 83-87.

6. Zhu, S.X. Research on Rice Farmer's Cognition for GM Rice, Willingness of Growing and Its Influence Factors-Based on Empirical Analysis on Rice Farmers in Huaian City, Jiangsu Province [J]. Scientific Management Research, 2011(21): 211-214.

7. Li, D.M., Liu, Z., Tang, S., etc.. Analysis on Willingness of Farmers to Select New Types of Rice and Its Influence Factors-Based on Investigation of 402 Farmers in Main Producing Area of Rice in Sichuan Province [J]. Agricultural Economic Issues, 2009(11): 44-50.

8. Luo, L. Analysis on Regional Difference of Southern Rice Farmer's Behavior of Updating the Type and Its Influence Factors [J]. Hunan Agricultural Science, 2012(08): 44-46.

9. Xu, D.Y. Production Cooperation and Avoidance of Fake Agricultural Material Infringement: A Theoretical Interpretation for Farmer Game [J]. Finance and Trade Research, 2010(2): 5862.

10. Pan, Y.H., Zhang, N.N. Investigation on Introduction of Transnational Seed Industry Companies and Mode of Seed Purchase and Use for Vegetable Farmers [J]. Agricultural Economic Issues, 2011(8): 10-18+110.

11. Ren, K.S. Empirical Research on Farmer's Application Behavior in the Circulation of New Types and Its Influence Factors [D]. Wuhan: Huazhong Agricultural University, 2008.

12. Sun, J., Huang, Z.H. Empirical Research on Farmer's Behavior of Selecting Agricultural Service Channels and Its Influence Factors [J]. Agricultural Technology Economics, 2009(1): $67-74$. 